\title{
Characterization of a Glucose Sensor Prepared by Electropolymerization of Pyrroles Containing a Tris-bipyridine Osmium Complex
}

\author{
Masaki Tsujimoto,* Tomoki Yabutani,* Atsushi Sano,* Yuji Tani,* Hiroki Murotani,* \\ Yuji Mishima, $* *$ Kenichi Maruyama, $* * *$ Mikito Yasuzawa, $*$ and Junko MotonaKa $* \dot{*}$ \\ *Department of Chemical Science and Technology, Faculty of Engineering, The University of Tokushima, \\ Minamijosanjima 2-1, Tokushima 770-8506, Japan \\ **Takasago Technical Center, Tsurui Chemical Co. Ltd., 2-1-1 Niihama Araicho, Takasago, \\ Hyogo 676-0008, Japan \\ ***Departments of Applied Chemistry and of Information and Computer Science, Faculty of Science and \\ Technology, Keio University, 3-14-1 Hiyoshi, Kohoku, Yokohama, Kanagawa 223-8522, Japan
}

\begin{abstract}
A glucose sensor was developed by electrocopolymerization using pyrroles containing a tris-bipyridine (bpy) osmium complex (Os-py), pyrrole (py), pyrrole propanoic acid (PPA) and glucose oxidase (GOx) to improve the key performance characteristics, such as the sensitivity, selectivity, and long-term stability. Tris-bipyridine osmium pyrrole complexes with four different methylene moieties were utilized to correlate the methylene length with the glucose sensor performance. The electrocatalytic response of glucose was clearly observed at electrodes modified with Os-py, except for the electrode immobilized with the Os-py complex containing the shortest methylene moiety. The current response to glucose increased up to a concentration of $100 \mathrm{mmol} \mathrm{dm}^{-3}$. The electrocatalytic response to glucose at the $\left[\mathrm{Os}(\mathrm{bpy})_{2} \text { (py(6)-bpy) }\right]^{2+/ 3+} / \mathrm{py} / \mathrm{PPA} / \mathrm{GOx}$ electrode was stable for more than 100 days. Dissolved oxygen and potential interference compounds (ascorbic acid, uric acid, and acetaminophen) minimally perturbed the current response to glucose at the $\left[\mathrm{Os}(\mathrm{DM}-\mathrm{bpy})_{2}(\mathrm{py}(6)-\mathrm{bpy})\right]^{2+/ 3+} / \mathrm{py} / \mathrm{PPA} / \mathrm{GOx}$ electrode. Based on these results, a longer methylene moiety appears to improve the performance characteristics of a glucose sensor fabricated via the electropolymerization of trisbipyridine osmium pyrrole complexes.
\end{abstract}

(Received September 8, 2006; Accepted November 6, 2006; Published January 10, 2007)

\section{Introduction}

A significant effort has been devoted to the development of new biosensors for the detection of biologically important species (e.g. glucose). Enzyme utilization in biosensors can provide selective, rapid and easy detection for use in clinical applications and research. ${ }^{1,2}$ Glucose is one of the most important analytes in the clinical field, particularly to determine accurate therapeutic treatments of diabetes. ${ }^{3}$ Glucose sensors modified with glucose oxidase (GOx) have been extensively researched to improve their performance. ${ }^{4,5}$

For constructing enzyme sensors, mediators are often used for shuttling electrons between the enzyme cofactor (e.g. FAD) and the electrode. ${ }^{6}$ Metallic compounds, such as ferrocene, ruthenium complexes, and osmium complexes, have been widely used as mediators due to their high chemical stability and rapid electron-transfer rate. $^{7-11}$ Since tris-bipyridine osmium complexes have higher self-electron transfer rates than ruthenium complexes and ferrocene compounds, their uses for amperometric biosensors have been shown to provide high sensitivity and low interference effects in biological samples. ${ }^{12,13}$

$\dagger^{\dagger}$ To whom correspondence should be addressed.

E-mail: motonaka@chem.tokushima-u.ac.jp
However, the immobilization methods and specific complex composition can significantly affect the enzyme sensor performance.

The immobilization of enzymes and mediators on the surface of electrodes has been performed by electrochemical polymerization, ${ }^{14,15}$ the formation of a gel polymer, ${ }^{16,17}$ and the formation of a self-assembled monolayer. ${ }^{18}$ An advantage of electropolymerization is the controlled formation of a polymer film while entrapping biomolecules to form the biologically active site of enzyme sensors. Furthermore, electropolymerization provides gentle entrapment in the polymer matrix, which does not disrupt the biologically active conformation of enzymes. Pyrrole compounds have been widely used as a material for electropolymerization.

Recently, mediator-pyrrole complexes have been proposed for fabricating reagentless enzyme sensors in which both the enzyme and the mediator are simultaneously immobilized on the surface of the electrodes. ${ }^{19}$ We have previously developed and studied Os-py in conjunction with the immobilization of enzymes for preparing glucose sensors. ${ }^{20,21}$ In this research, we synthesized several Os-pys, which were $\left[\mathrm{Os}(\mathrm{bpy})_{2}(\mathrm{py}(4)\right.$ bpy) $]^{2+/ 3+}, \quad\left[\mathrm{Os}(\mathrm{bpy})_{2}(\mathrm{py}(3)-\mathrm{bpy})\right]^{2+/ 3+}, \quad\left[\mathrm{Os}(\mathrm{bpy})_{2}(\right.$ py-pyridine $)-$ $\mathrm{Cl}^{+/ 2+}$ and $\left[\mathrm{Os}(\mathrm{bpy})_{2} \text { (vinyl-bpy) }\right]^{2+/ 3+}$, and characterized the prepared sensors. The $\left[\mathrm{Os}(\mathrm{bpy})_{2}(\mathrm{py}(4)-\mathrm{bpy})\right]^{2+13+}$ effectively acted as a mediator and immobilized materials for GOx 
compared to other Os-py compounds. However, the long-time stability of the response was found to be only ten days. Therefore, the structure of the Os-py affects the performance, such as the sensitivity and the long-time stability of the pyrrolemodified sensors. On the other hand, the effect caused from the structure of Os-py to the performances, such as its long-time stability and selectivity, has not been known. In relation to this topic, Yasuzawa et al. has reported that the performance of the glucose sensor prepared with gluconyl containing pyrroles having 6 methylene length of the $N$-derivatized group was better than that with a 3 methylene chain. ${ }^{22}$

In the case of developing a biosensor for detecting biological compounds, concomitant compounds, such as ascorbic acid, urea, uric acid and so on, in biological samples often cause serious interferences due to their direct oxidation on the electrode surface. The redox potential of mediator for the biosensor affects interfering level from concomitant compounds. ${ }^{12}$ Thus, it is desirable to use the mediators with a low redox potential because the direct oxidation of these compounds in this analytical condition is significantly observed at higher potentials than $300 \mathrm{mV}$ vs. $\mathrm{Ag} / \mathrm{AgCl}$. The redox potential of osmium complexes are controllable to be low by introducing the electron-donating groups, such as the methyl group and the amino group into the bipyridine of the Os(bpy $)_{3}$ because the back donation effect from the electron-donating groups to the bipyridine. ${ }^{12}$

In this work, the primary aim for using these pyrroles, which were $\left[\mathrm{Os}(\mathrm{bpy})_{2}(\mathrm{py}(6)-\mathrm{bpy})\right]^{2+/ 3+}$ and $\left[\mathrm{Os}(\mathrm{DM}-\mathrm{bpy})_{2}(\mathrm{py}(6)-\right.$ bpy) $]^{2+/ 3+}$ in Fig. 1, was to correlate the methylene length with the performance of the glucose sensors. We synthesized two Os-pys: $\left[\mathrm{Os}(\mathrm{bpy})_{2}(\mathrm{py}(6)-\mathrm{bpy})\right]^{2+/ 3+}$ and $\left[\mathrm{Os}(\mathrm{DM}-\mathrm{bpy})_{2}(\mathrm{py}(6)-\right.$ bpy) $]^{2+/ 3+}$. The $\left[\mathrm{Os}(\mathrm{DM}-\mathrm{bpy})_{2}(\mathrm{py}(6)-\mathrm{bpy})\right]^{2+/ 3}$ was designed for the purpose of having a lower redox potential than that of $\left[\mathrm{Os}(\mathrm{bpy})_{2}(\mathrm{py}(6)-\mathrm{bpy})\right]^{2+/ 3+}$. Furthermore, to ascertain the function in a complex biological sample, the developed glucose sensors were used to determine the glucose concentration in bovine serum.

\section{Experimental}

\section{Reagents}

GOx (EC 1.1.3.4 Type X-S: from Aspergillus niger), DM-bpy and pyrrole were purchased from Sigma-Aldrich (USA). D(+)Glucose and bpy were obtained from Kanto Kagaku (Japan). Py(6)-bpy and py(4)-bpy were synthesized in this laboratory. PPA was synthesized according to a reported procedure using 1(2-cyanopropyl) pyrrole purchased from Tokyo Chemical Industries (Japan). ${ }^{23}$ A stock glucose solution (500 $\mathrm{mmol} \mathrm{dm}^{-3}$ ) was prepared in a $0.067 \mathrm{~mol} \mathrm{dm}^{-3}$ phosphate buffer solution (PBS), pH 7.0, containing $0.1 \mathrm{~mol} \mathrm{dm}^{-3} \mathrm{NaCl}$ and stored at $4^{\circ} \mathrm{C}$ before use. All analytical solutions were prepared with ultrapure water.

Synthesis of the pyrroles containing a tris-bipyridine osmium complex

The $\operatorname{py}(n)$-bpys were synthesized with 1-(n-bromoalkyl)pyrrole and 4,4'-dimethyl-2,2' bipyridine through the Grignard reaction. ${ }^{21}$ Pyrroles containing the tris-bipyridine osmium complex, ([OsL $\left.\mathrm{O}_{2}(\mathrm{py}(n)-\mathrm{bpy})\right]{ }^{2+/ 3+} \mathrm{Cl}_{2}$; L represents bpy or DMbpy), were synthesized according to a method described by Maruyama et al. ${ }^{21}$ In the first step, $\left[\mathrm{OsL}_{2}(\mathrm{py}(n)-\mathrm{bpy})\right]^{2+/ 3+}\left(\mathrm{PF}_{6}\right)_{2}$ was prepared by mixing py(n)-bpy and $\mathrm{OsL}_{2} \mathrm{Cl}_{2} \cdot{ }^{24}$ After that, $\left[\mathrm{OsL}_{2}(\mathrm{py}(n)-\mathrm{bpy})\right]^{2+/ 3+} \mathrm{Cl}_{2}$ was obtained by an anion-exchange treatment.

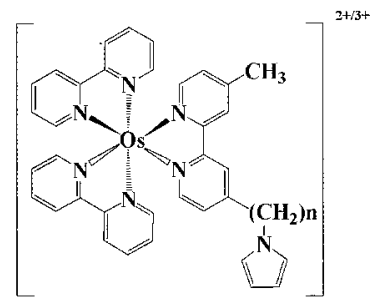

(A)

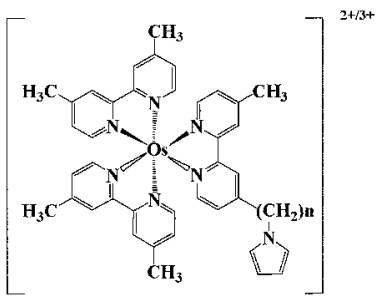

(B)
Fig. 1 Structural formula of $\left[\mathrm{Os}(\mathrm{bpy})_{2}(\mathrm{py}(n)-\mathrm{bpy})\right]^{2+/ 3+}$ (A) and [Os(DM-bpy $)_{2}(\text { py }(n) \text {-bpy) }]^{2+3+}(\mathrm{B})$. py $(n)$-bpy, $n$-(n-pyrrole-1-ylbutyl)$n^{\prime}$-methyl-2,2'-bipyridine; bpy, 2,2'-bipyridine; DM-bpy, 4,4'dimethyl-2,2'-bipyridine. The " $n$ " indicates the number of alkyl chains between the bipyridine in the tris-bipyridine osmium complex and the pyrrole molecule.

\section{Apparatus}

Electrochemical polymerization and measurements were carried out with a BAS CV-50W electrochemical analyzer (Bioanalytical Systems, Inc.). The electrochemical cell was composed of an $\mathrm{Ag} / \mathrm{AgCl}$ saturated $\mathrm{KCl}$ reference electrode, a platinum wire counter electrode and a platinum or glassy carbon (GC) working electrode (inner diameter of electrode; $3.0 \mathrm{~mm}$ ). Prior to use, the working electrode was sequentially polished with $6 \mu \mathrm{m}$ and $1 \mu \mathrm{m}$ of diamond slurry and $0.05 \mu \mathrm{m}$ alumina slurry. After trace alumina on the surface of the electrode was removed by water and cleaned by ultrasonication, the condition of the electrode surface was checked by cyclic voltammetry with a $1.1 \mathrm{mmol} \mathrm{dm}^{-3}$ potassium ferricyanide solution containing $0.1 \mathrm{~mol} \mathrm{dm}^{-3} \mathrm{NaCl}$.

\section{Preparation of working electrode}

Preparation of the working electrode was performed according to a previous report. ${ }^{25}$ A polished Pt electrode was cleaned by electrochemical etching in $0.5 \mathrm{mmol} \mathrm{dm}^{-3} \mathrm{H}_{2} \mathrm{SO}_{4}$ by cycling the electrode potential between -200 and $1400 \mathrm{mV}$ vs. $\mathrm{Ag} \mid \mathrm{AgCl}$ until a reproducible cyclic voltammogram was obtained. $\mathrm{A} \mathrm{pH}$ 7.0 phosphate buffer solution of a pyrrole containing trisbipyridine osmium complex $\left(0.5 \mathrm{mmol} \mathrm{\textrm {dm } ^ { - 3 }}\right)$, PPA $(10 \mathrm{mmol}$ $\left.\mathrm{dm}^{-3}\right)$, pyrrole $\left(2.5 \mathrm{mmol} \mathrm{dm}^{-3}\right), \mathrm{KCl}\left(0.1 \mathrm{mmol} \mathrm{dm}^{-3}\right)$ and GOx $\left(1.0 \mathrm{mg} \mathrm{dm}^{-3}\right)$ was placed in an electrochemical cell. Dissolved oxygen was removed from the solution by purging with $\mathrm{N}_{2}$ gas. An $\left[\mathrm{OsL}_{2}(\mathrm{py}(n)-\mathrm{bpy})\right]^{2+/ 3+} / \mathrm{py} / \mathrm{PPA} / \mathrm{GOx}$ film was electropolymerized on a clean Pt electrode by scanning the electrode potential between -400 and $1200 \mathrm{mV}$ for 100 cycles under a $\mathrm{N}_{2}$ atmosphere. Throughout this work, the $\left[\mathrm{OsL}_{2}(\operatorname{py}(n)-\right.$ bpy) $]^{2+13+} /$ py/PPA/GOx electrode was referred as an $\mathrm{OsL}_{2}(\operatorname{py}(n)-$ bpy) electrode. The modified electrode was washed with distilled water and stored in $\mathrm{pH}$ 7.0 $\mathrm{PBS}$ at $4^{\circ} \mathrm{C}$ until its use.

\section{Electrochemical measurement}

All of the electroanalytical experiments were performed by using the potentiostat a BAS-100B/W (BAS Inc.) equipped with a three-electrode system. All of the potentials were referred to an $\mathrm{Ag} / \mathrm{AgCl}$ electrode. Before the electrochemical measurement, $\mathrm{N}_{2}$ gas was thoroughly passed into the sample solution, and then, the flow of nitrogen gas was maintained over the solution during the measurement. The cyclic voltammograms were recorded at scan rate of $20 \mathrm{mV} \mathrm{s}^{-1}$. The applied potential in the experiment of the interference of concomitant compound was set at $550 \mathrm{mV} v s$. $\mathrm{Ag} \mid \mathrm{AgCl}$ with an Os(bpy $)_{2}$ (py(6)-bpy) electrode and $450 \mathrm{mV}$ with an Os(DMbpy) $)_{2}$ (py(6)-bpy) electrode. 
Table 1 Electrochemical parameters of the Os-pys $(\mathrm{mV} v s$. $\mathrm{Ag} \mid \mathrm{AgCl})$

\begin{tabular}{ccc}
\hline Os-py & $E_{1 / 2}$ & $\Delta E$ \\
\hline$\left[\mathrm{Os}(\mathrm{bpy})_{2}(\mathrm{py}(4)-\mathrm{bpy})\right]^{2+/ 3+}$ & 579.5 & 83.0 \\
{$\left[\mathrm{Os}(\mathrm{bpy})_{2}(\mathrm{py}(6)-\mathrm{bpy})\right]^{2+/ 3+}$} & 617.5 & 77.0 \\
{$\left[\mathrm{Os}(\mathrm{DM}-\mathrm{bpy})_{2}(\mathrm{py}(6) \text {-bpy })\right]^{2+/ 3+}$} & 499.5 & 98.0 \\
\hline
\end{tabular}

\section{Results and Discussion}

\section{Electrochemical properties of Os-py}

The mediation effects of the Os-py's were examined in a nonimmobilized system by cyclic voltammetry. Measurements of the non-immobilized system were performed in a solution of 1.0

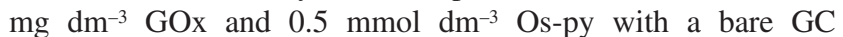
electrode. Figure 2 shows voltammograms at the electrode in the non-immobilization system with and without glucose. The Os-py effectively functioned as a mediator, since the electrocatalytic oxidation current was obviously observed with adding glucose. The electrochemical parameters of the Os-py's obtained by these experiments are listed in Table 1. The redox potentials of $\left[\mathrm{Os}(\mathrm{bpy})_{2}(\mathrm{py}(4)-\mathrm{bpy})\right]^{2+/ 3+}$ and $\left[\mathrm{Os}(\mathrm{bpy})_{2}(\mathrm{py}(6)-\right.$ bpy) $]^{2+13+}$ were observed around $600 \mathrm{mV}$, and that of [Os(DMbpy $)_{2}(\text { py(6)-bpy) }]^{2+13+}$ was shifted toward a negative potential at $450 \mathrm{mV}$. The lower shift of the redox potential for the [Os(DMbpy $)_{2}(\text { py(6)-bpy) }]^{2+/ 3+}$ is most likely due to a back-donation effect from the methyl groups to the bipyridine. ${ }^{12}$ The Nernstian difference between the redox potential peaks ( $\Delta E$ about $70-90$ $\mathrm{mV}$ ) and the even distribution of the reduced and oxidized species seen in the cyclic voltammogram indicates a reversible, or semi-reversible one-electron transfer reaction.

Performance characteristics of the Os-py modified working electrodes

Polypyrrole films composed of Os-py, pyrrole propanoic acid (PPA), pyrrole (py) and GOx were immobilized on Pt electrodes by electrocopolymerization. The PPA and py were added to improve the hydrophilic properties and the degree of polymerization for the electropolymerized polymer. ${ }^{21}$ Figure 3 shows the cyclic voltammogram in the presence or absence of glucose at the Os(bpy $)_{2}$ (py(6)-bpy) electrode. The increase in the electrocatalytic current was observed upon the addition of glucose to the sample solution. The electrocatalytic responses at the Os(bpy $)_{2}$ (py(4)-bpy) and Os(DM-bpy $)_{2}$ (py(6)-bpy) electrode were similar to that of the Os(bpy $)_{2}$ (py(6)-bpy) electrode. Electrocatalytic currents were absent from electrodes where GOx was not immobilized with Os-py. Because both the tris-bipyridine osmium complex and GOx were required to observe the electrocatalytic currents, the transfer of electrons between GOx and the electrode was mediated by the trisbipyridine osmium complex.

The long-term stability of the Os-py modified electrode was examined by measuring the current response at a $550 \mathrm{mV}$ applied potential. In the experiment, the electrode was tested in a $20.0 \mathrm{mmol} \mathrm{dm}^{-3}$ glucose solution with $0.1 \mathrm{~mol} \mathrm{dm}^{-3} \mathrm{NaCl}$, and stored in $\mathrm{pH} 7.0$ phosphate buffer at $4^{\circ} \mathrm{C}$ between the measurements. The result is given in Fig. 4. The relative response at a Os(bpy $)_{2}(\mathrm{py}(6)$-bpy) electrode was maintained at $90 \%$ for over 100 days, while the response of a Os(bpy $)_{2}(\mathrm{py}(4)-$ bpy) electrode decreased to $40 \%$ after 20 days. The shorter methylene group of the Os(bpy) 2 (py(4)-bpy) electrode may cause inadequate entrapment and thus, the loss of the enzyme

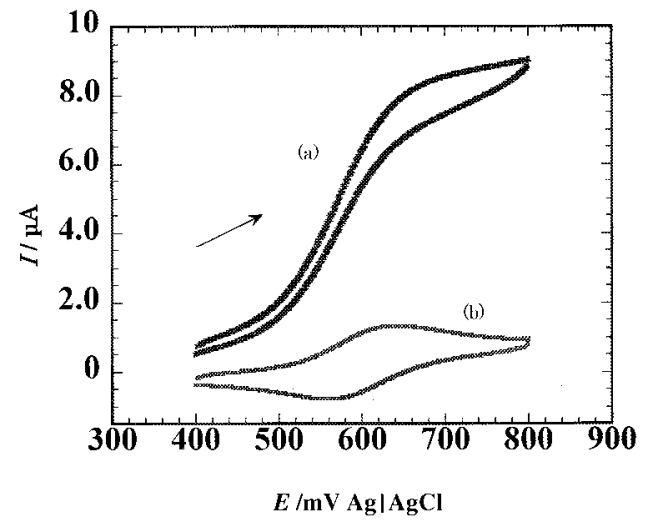

Fig. 2 Cyclic voltammograms of electro-catalytic oxidation of glucose at a bare glassy carbon electrode in the non-immobilized system. Sample: $5 \mathrm{ml} \mathrm{pH} \mathrm{7.0} \mathrm{PBS} \mathrm{containing} 0.5 \mathrm{mmol} \mathrm{dm} \mathrm{dm}^{-3}$ Os-py, $100 \mathrm{mmol} \mathrm{dm}^{-3} \mathrm{NaCl}$ and $1.0 \mathrm{mg} \mathrm{dm}^{-3} \mathrm{GOx}$ with (a) and without 20 $\mathrm{mmol} \mathrm{dm}{ }^{-3}$ glucose (b) at room temperature.

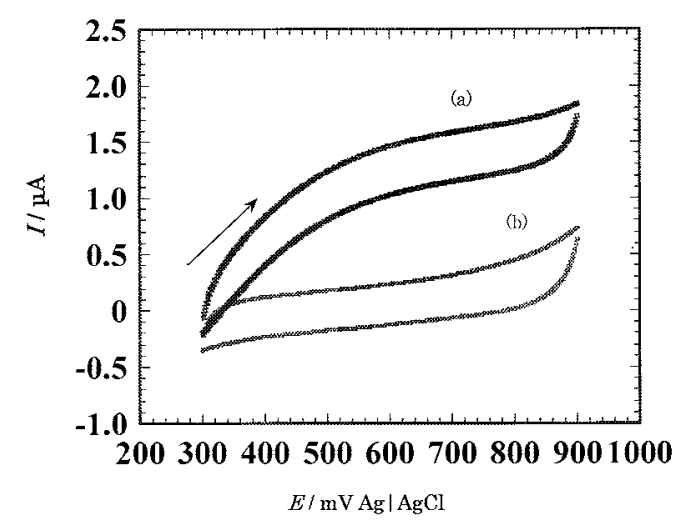

Fig. 3 Cyclic voltammograms of electrocatalytic oxidation of glucose at an Os(bpy) $)_{2}(\mathrm{py}(6)$-bpy) electrode. Sample: $5 \mathrm{ml} \mathrm{pH} 7.0$ PBS with (a) and without $20 \mathrm{mmol} \mathrm{dm}^{-3}$ glucose (b) at room temperature. Scan rate was $10 \mathrm{mV} \mathrm{s}^{-1}$ in the both measurements.

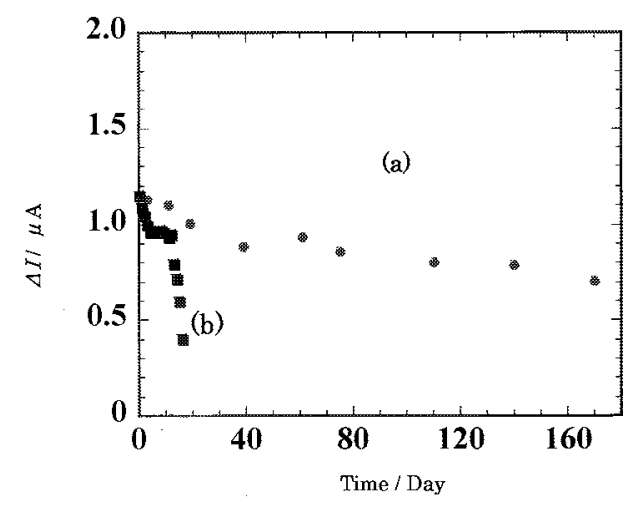

Fig. 4 Comparison of the long-term stability at an Os(bpy $)_{2}(\mathrm{py}(6)$ bpy) electrode (a) versus an Os(bpy) $)_{2}(\mathrm{py}(4)$-bpy) electrode (b). The electrode was stored at $4^{\circ} \mathrm{C} . \Delta I=$ current response day $1 /$ current response day $(1+n)$

from the loose polymer network during storage. The loss of glucose oxidase from a pyrrole polymer network has been observed in the case of using pyrrole for the entrapment of 
Table 2 Relative error (\%) of glucose in the presence and the absence of the concomitant compounds

\begin{tabular}{cccc}
\hline Electrode & Ascorbic acid $\left(0.11 \mathrm{mmol} \mathrm{dm}^{-3}\right)$ & Uric acid $\left(0.48 \mathrm{mmol} \mathrm{dm}^{-3}\right)$ & Acetaminophen $\left(0.12 \mathrm{mmol} \mathrm{dm}^{-3}\right)$ \\
\hline Os(bpy) 2 (py(6)-bpy) & 6 & 13 & 20 \\
Os(DM-bpy) $($ py(6)-bpy) & 3 & 9 & 11 \\
\hline
\end{tabular}

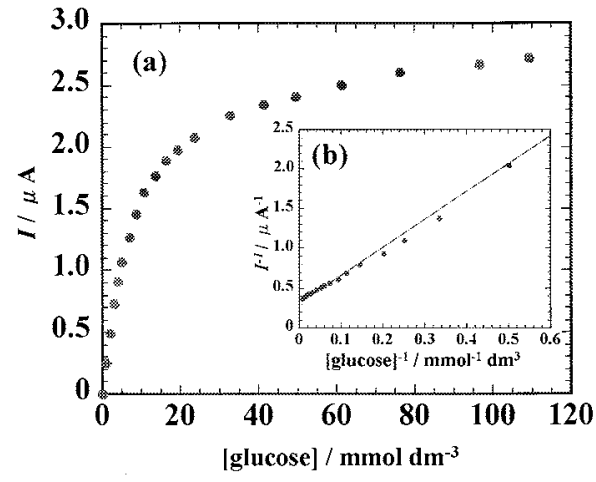

Fig. 5 Calibration plots for the oxidation of glucose with an Os(bpy) $)_{2}($ py(6)-bpy) electrode (a) and a Lineweaver-Burk plot (b).

GOx. ${ }^{26}$ Similar phenomena were observed on a GOx immobilized electrode prepared by the electropolymerization of pyrrole derivatives containing a gluconyl terminal group at the 1-position.22 It is well known that the electroconductivity of pyrrole polymer is lowered by introducing a substituent at the 1position of pyrrole, and a substituent with a longer methylene chain normally leads to a lower conductivity polymer. However, the existence of a bulky substituent close to the pyrrole ring interrupts the planar structure of the $\pi$-conjugated pyrrole rings of the polymer, which prevents an increase of the polymerization degree of the obtained polypyrrole. Therefore, the separation of the pyrrole ring and the bulky osmium complex by the introducing a methylene chain with a certain length, relieves the formation of a planar structure of the pyrrole ring and leads to an increase of the electroconductivity and the polymerization degree of the enzyme immobilizing polymer.

A calibration plot for glucose at an Os(bpy) 2 (py(6)-bpy) electrode is shown in Fig. 5, including a Lineweaver-Burk plot (inset). The calibration plot indicates a response of the Michaelis-Menten type in the concentration range from 0 to 100 mmol dm $\mathrm{dm}^{-3}$ for glucose. The Michaelis-Menten constants $\left(K_{\mathrm{m}}^{\text {app }}\right)$ for $\mathrm{Os}(\mathrm{bpy})_{2}(\mathrm{py}(4)-\mathrm{bpy}), \quad \mathrm{Os}(\mathrm{bpy})_{2}(\mathrm{py}(6)-\mathrm{bpy})$ and Os(DM-bpy $)_{2}($ py(6)-bpy) electrodes were 27.1, 27.8, and 21.8 mmol dm${ }^{-3}$, respectively.

The effect from interference compounds and an application to a bovine serum sample

For a mediator-type enzyme sensor, oxygen often competes with a mediator as an electron donor. The interference effect of oxygen was determined by measuring the current response in an oxygen-saturated solution versus that in a nitrogen-saturated solution. The relative error at the Os(bpy $)_{2}(\mathrm{py}(6)$-bpy) electrode was $6 \%$. The interference from dissolved oxygen at the Os-py modified electrode was suppressed, compared to the relative error observed at the bis-bipyridine osmium complex-modified electrode. The high electron-transferring rate of the trisbipyridine osmium complex in the Os-py could provide the suppression of interference from oxygen. ${ }^{13}$

The potential interference responses were checked in the presence of concomitant compounds (typical in the biological samples) and glucose at the Os-py modified electrodes. The concentrations of the interference compounds were adjusted to the physiological maximum concentration in human serum. In this study, the relative error was estimated boned on the current response at $5.6 \mathrm{mmol} \mathrm{dm}{ }^{-3}$ of glucose. The data are given in Table 2. The relative error at the Os(DM-bpy) $)_{2}(\mathrm{py}(6)-\mathrm{bpy})$ electrode was $3 \%$ for ascorbic acid, $9 \%$ for uric acid, and $11 \%$ for acetaminophen. The responses from the interference compounds observed at the Os(DM-bpy $)_{2}(\mathrm{py}(6)$-bpy) electrode were slightly lower than that at the Os(bpy $)_{2}(\mathrm{py}(6)$-bpy) electrode, although the maximum response $\left(V_{\max }\right)$ of glucose at the $\left[\mathrm{Os}(\mathrm{DM}-\mathrm{bpy})_{2}(\mathrm{py}(6)-\mathrm{bpy})\right]^{2+/ 3+}$ electrode was $2.0 \mu \mathrm{A}$, and was lower than that at the $\left[\mathrm{Os}(\mathrm{bpy})_{2}(\mathrm{py}(6)-\mathrm{bpy})\right]^{2+/ 3+}$ electrode $(2.5 \mu \mathrm{A})$. Therefore, the low redox potential of the [Os(DMbpy $)_{2}(\text { py(6)-bpy) }]^{2+13+}$ compared with that of the $\left[\mathrm{Os}(\mathrm{bpy})_{2-}\right.$ (py(6)-bpy) $]^{2+13+}$ could provide the suppression of interferences of the direct oxidation generated at a relatively high potential.

The Os(bpy $)_{2}(\mathrm{py}(6)-\mathrm{bpy})$ and the Os(DM-bpy $)_{2}(\mathrm{py}(6)-\mathrm{bpy})$ electrodes were used to measure the glucose concentration in a bovine serum sample (Nippon Biotest Laboratories Inc.). The determined values in this work were 5.96 and $4.44 \mathrm{mmol} \mathrm{dm}^{-3}$ for an Os(bpy $)_{2}(\mathrm{py}(6)-\mathrm{bpy})$ electrode and Os(DM-bpy $)_{2}(\mathrm{py}(6)-$ bpy) electrode, respectively. The value obtained at the Os(DMbpy $)_{2}$ (py(6)-bpy) electrode was in good agreement with the recommended value $\left(4.55 \mathrm{mmol} \mathrm{\textrm {dm } ^ { - 3 }}\right)$ estimated from the manufacturer. The lower redox potential of the Os(DMbpy $)_{2}$ (py(6)-bpy) electrode was effective in eliminating the interference response for a more accurate glucose determination in a biological sample.

\section{Conclusions}

We have developed and characterized a glucose sensor using Os-pys. In this work, we showed that Os-py is effective as a mediator and an immobilization matrix for glucose oxidase, compared to the bis-type osmium complex immobilized electrode, because of the relative high electron transferring rate. The length of the methylene chains between the tris-osmium complex and the pyrrole contributed to the long-term stability for this electrode. It is proposed that these effects were due to the polymerization process of the polypyrrole chain. The potential control using the Os(DM-bpy $)_{2}(\mathrm{py}(6)-\mathrm{bpy})$ was effective in reducing interferences from the concomitant compounds. It is expected that osmium complexes having a lower redox potential than Os(DM-bpy $)_{2}$ (py(6)-bpy) would also be useful for reducing interference from the concomitant compound. The incorporation of amino or dimethylamino groups will give the osmium complex a large shift toward a negative potential, since the groups have a large back donation effect of the $\pi$ electron to the bipyridine group of the osmium complex.

\section{Acknowledgements}

The present work was supported by Grants-in-Aid of Scientific 
Research (No. 17750071), from the Ministry of Education, Culture, Sports, Science and Technology of Japan.

\section{References}

1. A. Chaubey and B. D. Malhotra, Biosens. Bioelectron., 2002, 17, 441.

2. W. Zhang and G. Li, Anal. Sci., 2004, 20, 603.

3. J. Wang, Electroanalysis, 2001, 13, 983.

4. L. Gorton, G. Bremle, E. Csoeregi, G. Joensson-Pettersson, and B. Persson, Anal. Chim. Acta, 1991, 249, 43.

5. M. Staiano, P. Bazzicalupo, M. Rossi, and S. D'Auria, Mol. Biosystems, 2005, 1, 354.

6. K. Habermuller, M. Mosbach, and W. Schuhmann, Fresenius' J. Anal. Chem., 2000, 366, 560.

7. J. Kulys and N. K. Cenas, Biochim. Biophys. Acta, 1983, $744,57$.

8. P. Schlapfer, W. Mindt, and P. Racine, Clin. Chim. Acta, 1974, 57, 283.

9. A. E. G. Cass, G. Davis, M. J. Green, H. Hill, and O. Allen, J. Electroanal. Chem., 1985, 190, 117.

10. K. Yokoyama, E. Tamiya, and I. Karube, J. Electroanal. Chem., 1989, 273, 107.

11. S. M. Zakeeruddin, D. M. Fraser, M. K. Nazeeruddin, and M. Graetzel, J. Electroanal. Chem., 1992, 337, 253.

12. Y. Nakabayashi, A. Omayu, S. Yagi, K. Nakamura, and J.
Motonaka, Anal. Sci., 2001, 17, 945

13. Y. Nakabayashi, A. Omayu, S. Morii, and S. Yagi, Sens. Actuators, B, 2000, 66, 128.

14. J. Vidal, E. Garcia-Ruiz, and J.-R. Castillo, Microchim. Acta, 2003, 143, 93.

15. P. N. Bartlett and J. M. Cooper, J. Electroanal. Chem., 1993, 362,1 .

16. B. A. Gregg and A. Heller, Anal. Chem., 1990, 62, 258.

17. T. Yabutani, N. Okada, K. Maruyama, and J. Motonaka, Int. J. Modern Phys. B, 2003, 17, 1193.

18. W. Schuhmann, Rev. Mol. Biotechnol., 2002, 82, 425.

19. N. Gajovic, K. Habermüller, A. Warsinke, W. Schuhmann, and F. W. Scheller, Electroanalysis, 1999, 11, 1377.

20. J. Motonaka, T. Yabutani, K. Maruyama, T. Shiomi, N. Tateishi, and Y. Mishima, Bunseki Kagaku, 2002, 51, 1165.

21. K. Maruyama, Y. Mishima, and J. Motonaka, Anal. Sci., 2001, 17, i293.

22. M. Yasuzawa, S. Fujii, A. Kunugi, and T. Nakaya, Anal. Sci., 1999, 15, 1175.

23. M. Andrade, C. Sousa, J. E. Borges, and C. Freire, J. Phys. Org. Chem., 2005, 18, 935.

24. J. Wang, M. Pappalardo, and R. F. Keene, Aust. J. Chem., 1995, 48, 1425.

25. M. Tsujimoto, K. Maruyama, Y. Mishima, and J. Motonaka, Int. J. Modern Phys. B, 2003, 17, 1517.

26. M. Quino, I. Losito, F. Palmisano, and C. G. Zambonin, Anal. Chim. Acta, 2000, 420, 9. 